\title{
A minor but deadly surgery of colonic polypectomy in an elderly and fragile patient: a case report and the review of literature
}

Xiaoming Yuan ${ }^{1+}$, Guangrong Zhou ${ }^{1+}$, Yan $\mathrm{He}^{2}$ and Aiwen Feng ${ }^{1 *}$

\begin{abstract}
Background: Epithelial dysplasia and adenomatous polyps of colorectum are precancerous lesions. Surgical removal is still one of the important treatment approaches for colorectal polyps.

Case presentation: A male patient over 78 years was admitted due to bloody stool and abdominal pain. Colonoscopic biopsy showed a high-grade epithelial dysplasia in an adenomatous polyp of sigmoid colon. Anemia, COPD, ischemic heart disease (IHD), arrhythmias, and hypoproteinemia were comorbidities. The preoperative preparation was carefully made consisting of oral nutritional supplements (ONS), blood transfusion, cardiorespiratory management, and hemostatic therapy. However, his illness did not improve but deteriorate mainly due to polyp rebleeding during preparative period. The open polypectomy was performed within 60 min under epidural anesthesia. Postoperative treatments included oxygen inhalation, bronchodilation, parenteral and enteral nutrition, human serum albumin, antibiotics, and blood transfusion. Unluckily, these did not significantly facilitate to surgical recovery on account of severe comorbidities and complications. The most serious complications were colonic leakage and secondary abdominal severe infection. The patient finally gave up treatment due to multiple organ dysfunction syndromes.
\end{abstract}

Conclusions: The polypectomy for colonic polyp is a seemingly minor but potentially deadly surgery for patients with severe comorbidities, and prophylactic ostomy should be considered for the safety.

Keywords: Colonic polyp, Hypoproteinemia, Anemia, COPD, Arrhythmias, Polypectomy, Intestinal leakage, Abdominal infection

\section{Background}

Adenomatous polyp and epithelial dysplasia are regarded as precancerous lesions of colorectal cancer [1]. Endoscopic intervention (e.g., EMR/ESD) and surgical removal (e.g., polypectomy/colectomy) are important management approaches [1-3]. In general, surgical removal should be considered where the malignancy is suspected or concerns about the likelihood of incomplete endoscopic resection or endoscopic contraindications $[2,4]$. The limited surgical resection is fit for patients with comorbidities [2], but

\footnotetext{
* Correspondence: fengheyan-2000@163.com

${ }^{\dagger}$ Equal contributors

'Department of Intestinal Surgery, Affiliated Huai'an First People's Hospital,

Nanjing Medical University, Huai'an 223300, China

Full list of author information is available at the end of the article
}

prophylactic ostomy is not explicitly elaborated in many literatures [1-5]. In this case, we reported a case of deadly colonic leakage after laparotomic polypectomy for an adenomatous polyp of colon.

\section{Case presentation}

A male patient over 78 years was admitted on Sep. 9, 2015, due to bloody stool and abdominal pain. Past history included smoking, bronchitis, COPD, but no cirrhosis and nephrotic syndrome. Physical exam showed normal vital signs, lung hyperresonance, and scattered crackles. The abdomen was flat without GI pattern. Tenderness and rebound tenderness were negative. Right indirect hernia existed where gut were palpable. 
Mass, anal fissure, and hemorrhoid were not found in the rectum and anus. Lung function showed obstructive ventilation dysfunction (Table 1). ECG and Doppler echocardiography showed arrhythmias, ischemic heart disease (IHD), pulmonary hypertension, and reduced left ventricular compliance (Table 1). The heart function classification was II. Colonoscopy revealed a pedunculated and easy bleeding polyp of sigmoid colon, but did not find ischemic bowel disease, IBD, and diverticula. A biopsy for polyp samples showed high-grade epithelial dysplasia and adenomatous polyp (Table 1). CT scan showed emphysema, right hernia where gut could be watched, prostatic hyperplasia, and hepatorenal cysts, but no visible masses in GI tract (Table 1). Laboratory findings showed anemia, positive FOBT, and hypoproteinemia. The coagulation, hepatorenal function, and arterial blood gas were almost normal (Table 2). APACHE II score was 10 points. ASA classification grade was III. Goldman Cardiac Risk Index score and European Nutritional Risk Screening (NRS 2002) score were 15 and 3 points, respectively.

A 2-week preoperative preparation was made. Bronchitis and COPD were managed by stopping smoking, low-flow oxygen therapy, blowing balloon exercise, and administration of aminophylline and levofloxacin. Anemia was treated by blood transfusion of $4 \mathrm{U}$ PRBCs, bleeding by vitamin $\mathrm{K}$, and arrhythmias by $\beta$-receptor blocker. Malnutrition was treated by amino acid, dextrose, fatty emulsion, vitamins, and trace elements, as well as oral bifidobacteria and peptison based on dietary supplement. After treatment, lung scattered rales completely resolved. Nevertheless, anemia and hypoproteinemia did not significantly improve but deteriorate due to rebleeding from colonic polyp. Thus, laparotomic polypectomy was performed under epidural anesthesia on Sep. 23, 2015. An incision of the colonic wall was longitudinal and was sutured transversely. The operative time was $60 \mathrm{~min}$ and blood loss was little. Early postoperative management included respiratory management, restrictive fluid administration, combined antibiotics, octreotide, and parenteral nutrition $(25-30 \mathrm{kcal} / \mathrm{kg} /$ day). Human serum albumin was given at a dose of $10 \mathrm{~g}$ daily. During the first 3 days, the patient was uneventful and oral fluid diet containing ONS was provided after anal aerofluxus. At the fourth day, he suffered from acute heart dysfunction (AHD) diagnosed by manifestations of fatigue, dyspnea, oliguria, and pulmonary rales. ECG monitor showed normal BP, decreased $\mathrm{SaO}_{2} \%$, and increased heart rate. The CVP value was $>15 \mathrm{cmH}_{2} \mathrm{O}$. Re-assessment of cardiac function classification was IV. The clinical features of AHD rapidly resolved after injection of cardiotonic and diuretic. Laboratory test showed normal electrolytes and decreased $\mathrm{Hb}$ level $(78 \mathrm{~g} / \mathrm{L})$ (Table 2), so 1 U PRBCs were transfused. At the 7th day laboratory findings revealed abnormal renal function (Table 2). At the 10th day, he complained of abdominal distension and dramatic increase in volume of right hernia. B ultrasound revealed pleural effusion and massive ascites. Laboratory findings revealed worse renal function (Table 2). At the 11th day, he was re-struck by AHD, which was also rapidly corrected by cedilanid and furosemide. Massive pale yellow ascites outflowed from abdominal incision and abdominal drainage tube. At the 12th day, he had colonic leakage as judged by intestinal content outflowing from abdominal incision and drainage tube, which had drained out little pale bloody fluid and pale yellow ascites during past 11 days. At the 14th day, he gave up treatment due to severe infection and MODS (Table 2).

\section{Discussion}

Epithelial dysplasia and tumorous polyps are regarded as precursor lesions of large bowel carcinoma. The risk of adenomatous polyp is significantly increased in COPD patients [6]. In clinic, most polyps can be treated by EMR and ESD, and only a few cases need surgery [7]. In this case, the patient was not a good candidate for endoscopic management according to ESGE guideline [8]. A preparation was made according to preoperative evaluation including smoking history, cardiopulmonary function, nutritional status, and ASA classification. Unluckily, this preparation was depressing because anemia

Table 1 The examination findings before and after colonic polypectomy

\begin{tabular}{ll}
\hline Item & Examination findings \\
\hline ECG & Sinus tachycardia, frequent premature atrial complexes, occasional ventricular premature beat, ischemic ST-T change \\
CUS & Moderate pulmonary arterial hypertension, mild aortic valvular regurgitation, reduced left ventricular compliance \\
$\mathrm{CT}$ & $\begin{array}{l}\text { Bilateral emphysema, right indirect inguinal hernia, prostatic hyperplasia, hepatorenal cysts, normal esophagus/gastrointestine/colon, but } \\
\text { suspicious thickness of the upper rectum }\end{array}$ \\
PF & Severe mixed ventilation dysfunction, MV $20 \mathrm{~L} / \mathrm{min}(24 \%$ of predicated value), FEV1 0.72 (34\% of predicated value) \\
$\mathrm{CS}$ & A pedunculated neoplasm (3.0 $\times 2.0 \times 1.5 \mathrm{~cm}$ in size, villous and friable and easy bleeding) of sigmoid colon \\
POB & Colonic villioustublar adenoma in accompany with epithelial high-grade dysplasia \\
POP & Colonic villioustublar adenoma in accompany with epithelial high-grade dysplasia and focal canceration
\end{tabular}

ECG electrocardiography, CUS cardiac ultrasound, CT computed tomography, PF pulmonary function, MVV maximum ventilator volume, FEV1 forced expiratory volume in first second, $C S$ colonoscopy, $P O B$ preoperative biopsy, $P O P$ postoperative pathology 
Table 2 Laboratory examinations before and after colonic polypectomy

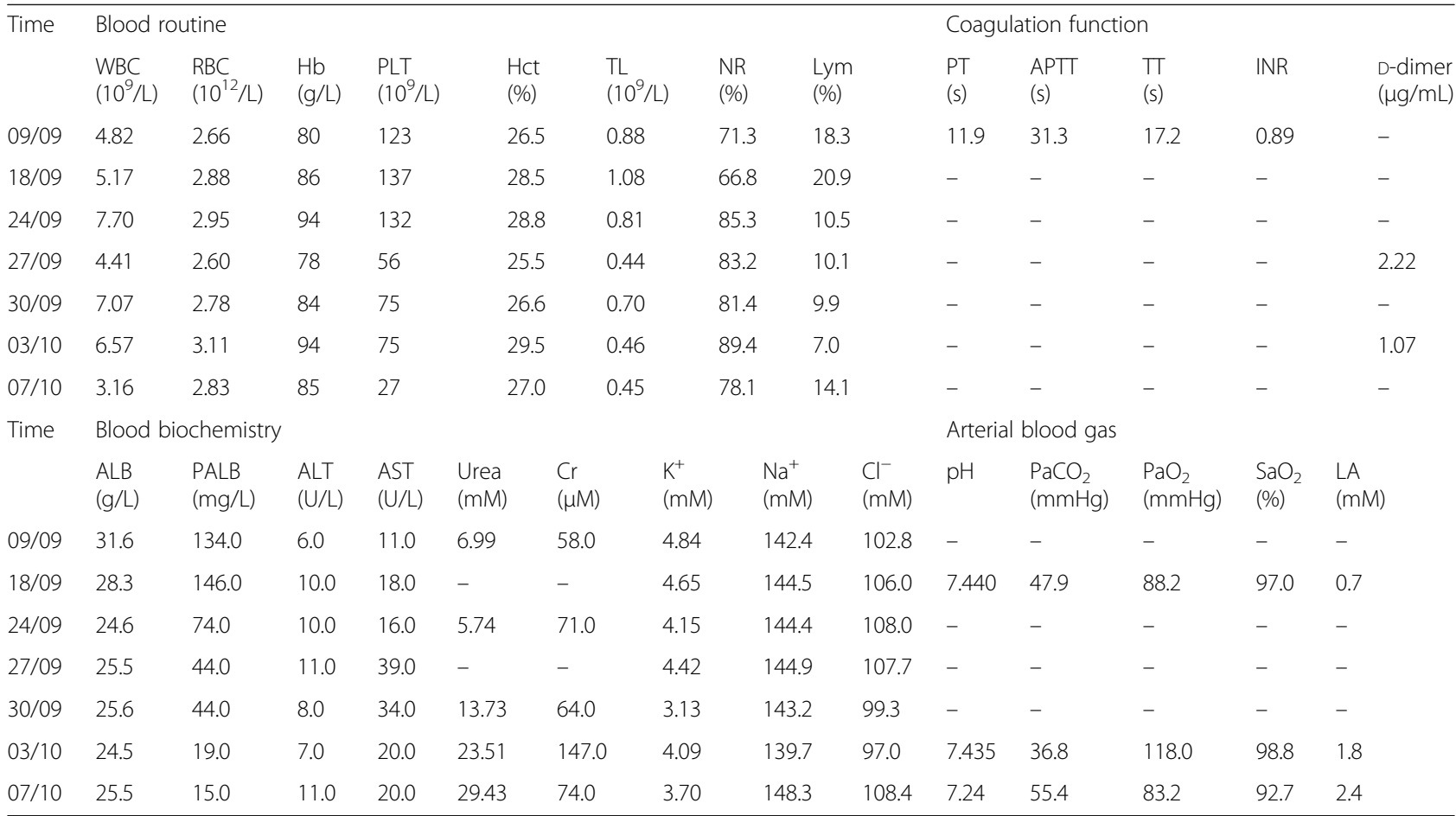

WBC white blood cell, $R B C$ red blood cell, $H b$ hemoglobin, $P L T$ platelet, Hct hematocrit, $T L$ total lymphocyte, NR neutrophil ratio, $L y m$ lymphocyte, $P T$ prothrombin time, $A P T T$ activated partial thromboplastin time, $T$ thrombin time, INR international normalized ratio, Fn fibrinogen, $A L B$ albumin, $P A L B$ pre-albumin, $A L T$ alanine aminotransferase, AST aspartate aminotransferase, $\mathrm{Cr}$ creatinine, LA lactic acid

and malnutrition (hypoproteinemia and reduced peripheral blood lymphocyte) did not improve but deteriorate (Table 2), which was associated with uncontrollable rebleeding from polyp. Thus, this polypectomy to some extent was done under a potential risk circumstance.

In order to minimize trauma, we selected small median incision and epidural anesthesia [9-11]. This polypectomy was performed in a short time. Postoperative measures were taken such as provision of nutritional support, human serum albumin, antibiotics, and cardiopulmonary management. Unluckily, severe comorbidities and complications including acute heart dysfunction, anemia, renal dysfunction, and malnutrition disturbed sickness recovery. The most serious complications were colonic leakage and severe abdominal infection, which generally carry a high mortality [12].

COPD is an irreversible and chronic inflammatory pulmonary disorder [13], and $25-40 \%$ patients with COPD are reported to be undernourished [14-16], as is referred to lung cachexia [13]. COPD and malnutrition are confirmed to be predictive markers for poor prognosis and high mortality $[13,17,18]$. The most important mechanism for COPD-induced malnutrition is the mismatching between protein biosynthesis and breakdown [14-16]. The adverse factors for malnutrition include disordered hormones [19], inflammatory cytokines (e.g., IL-6, TNF $\alpha$ [20], CRP [21]), cigarette smoking [22], poor physical activity [19], and hypoxemia [14, 19]. Further, serum total protein $\leq 55 \mathrm{~g} / \mathrm{L}$ and albumin $\leq 35 \mathrm{~g} / \mathrm{L}$ are predictors for gut leakage [23, 24]. In this case, severe COPD and malnutrition hypoproteinemia (Table 2) played an important role in leakage generation.

Age and gender are also independent risk factors for gut leakage. It is reported that the morbidity of gut leakage in patients $\geq 65$ years is 1.31 -fold compared to those $<65$ years [12]. Studies have further showed that elderly patients $\geq 75$ years [25] usually have reduced whole function reserve, more internal chronic diseases, worse operative tolerance, slower postoperative recovery, and higher complication and mortality rate [26, 27]. A prospective study by Kotoč et al. shows that the morbidity of anastomotic leakage in patients with sphincter-saving rectal resections is $10.9 \%$, and these patients all are males [18]. Another study report by Nasirkhan shows the morbidity of gut leakage in male patients $(13.4 \%)$ was significantly higher than that in female patients $(5.2 \%)$ [28]. In this case, the elderly age and male gender were harmful factors for leakage formation.

Anemia is a common comorbidity in patients with gastrointestinal disease, especially malignancy. Some studies suggested anemia is a negative factor for postoperative recovery. Hemoglobin $\leq 94 \mathrm{~g} / \mathrm{L}$ is an independent adverse prognostic factor for leakage [23]. Thus, correction of anemia constitutes an important component of 
perioperative managements. However, blood transfusion in turn may decrease body's immunocompetence [12]. It has been documented that blood transfusion of $>2 \mathrm{U}$ PRBCs may contribute to intestinal leakage generation $[22,24]$. Though these studies are all retrospective, further prospective studies we think are still needed. In this case, anemia and blood transfusion of $5 \mathrm{U}$ PRBCs were likely involved in facilitating to gut leakage.

Cigarette smoking has a detrimental action on healing of surgical wounds [29]. Tobacco consists of at least three toxic substances: nicotine, tar, and carbon monoxide. Studies have demonstrated that these toxins can contract blood vessels and reduce blood supply, accompanying with decrease in contractility of vessels, blood flow rate, and efficiency of oxygen transportation [30]. In addition, smoking may give rise to a significant decline in body's resistance to infection [30]. Recently, a large prospectively collected clinical database has indicated that smoking is associated with an increased risk of leakage [31]. In this case, long-term cigarette smoking inducing vessel contraction and hypoxia might play a role in disunion of colon-wall incision.

Cardiac dysfunction is closely associated with COPD, IHD, and volume overload. COPD and IHD are mutually influenced. Patients with COPD and IHD show worst outcomes compared to those with only COPD or IHD [32], as shown by an increase in risk of heart failure, acute exacerbation of COPD, and mortality [32, 33]. The mechanism of volume overload in COPD patients was the activation of sodium-retaining mechanisms [34]. COPD patients with hypoalbuminemia are also prone to develop acute heart dysfunction [35]. In addition, premature ventricular complexes have an adverse influence on pump function [36]. In this case, these factors such as COPD, IHD, hypoproteinemia, and arrhythmia to some extent participated in inducing acute heart dysfunction.

Epidural anesthesia is generally regarded as to be safe in many surgical operations [9-11]. Epidural anesthesia is observed to increase motor activity in the small bowel as well as left-sided colon and rectum. Tonic and segmental contractions are recorded from the sigmoid colon to rectum [37]. The increase of motor activity is often deemed as a marker of gut function recovery. However, increased motor activity may expose a constructed anastomosis to undue strain in the postoperative period [37], which is a detrimental factor to the healing of anastomosis [24]. In addition, it has been recently reported that an ASA score of $\geq 3$ is related to an increased risk of gut leakage [31]. In this case, the patient with a ASA score of 3 had a fast recovery of gut peristaltic function after epidural anesthesia, but this increased motor activity was also an adverse factor for incision healing of the sigmoid colon.

Prophylactic ostomy is used in certain operations for colorectal cancer [38, 39] and non-neoplasm diseases such as familial adenomatous polyposis and ulcer colitis $[40,41]$. Prophylactic ostomy can effectively prevent feces from inflowing into abdominal. However, prophylactic ostomy is not a routine surgical procedure for treating a single colorectal polyp. Thus, in this case, the patient was only done polypectomy without prophylactic colostomy. Unluckily, his multiple comorbidities and postoperative complications severely interfered with surgical incision healing, resulting in deadly colonic leakage and secondary diffuse abdominal infection.

\section{Conclusions}

Laparotomic polypectomy is a minor but potentially deadly operation for the very old and fragile patients with severe comorbidities, and prophylactic ostomy should be considered for the safety.

\section{Abbreviations}

AHD: Acute heart dysfunction; COPD: Chronic obstructive pulmonary disease; IBD: Inflammatory bowel disease; MODS: Multiple organ dysfunction syndrome; ONS: Oral nutritional supplements; PRBCs: Packed red blood cells

\section{Acknowledgements}

We thank Ti Zhang, who is the director of Department of Gastrointestinal Surgery, and Xiangwei Li for revising the manuscript critically for important intellectual content.

\section{Funding}

The authors declare that no funds have been received.

\section{Availability of data and materials}

The availability of the data and materials concerning the case report is related to all the diagnostic examinations that the patient has submitted during his hospitalization. The publication of all these data has been authorized by the Affiliated Huai'an First People's Hospital, Nanjing Medical University.

\section{Authors' contributions}

The original manuscript was written by $\mathrm{YH}$ and AF. In this revised manuscript the additional author XY made major contribution including surgical description, article revision, and literature supplement. All authors read and approved the final manuscript.

\section{Competing interests}

The authors declare that they have no competing interests.

\section{Consent for publication}

The consent for publication of the manuscript and the related tables from the patient has been obtained by the Affiliated Huai'an First People's Hospital of Nanjing Medical University.

\section{Ethics approval and consent to participate}

The ethical approval has been received by the Affiliated Huai'an First People's Hospital, Nanjing Medical University concerning the publication of this manuscript and any accompanying tables. A copy of this document is available for review by the Editor-in-Chief of this journal.

New software

The authors declare that no new software has been used.

\section{Author details}

'Department of Intestinal Surgery, Affiliated Huai'an First People's Hospital, Nanjing Medical University, Huai'an 223300, China. ²Department of Oncological Radiotherapy, Affiliated Huai'an First People's Hospital, Nanjing Medical University, Huai'an 223300, China. 
Received: 17 June 2016 Accepted: 21 September 2016 Published online: 26 September 2016

\section{References}

1. Conteduca V, Sansonno D, Russi S, Dammacco F. Precancerous colorectal lesions (Review). Int J Oncol. 2013;43:973-84.

2. Benedix F, Kockerling F, Lippert $\mathrm{H}$, Scheidbach $\mathrm{H}$. Laparoscopic resection for endoscopically unresectable colorectal polyps: analysis of 525 patients. Surg Endosc. 2008:22:2576-82.

3. Fu X, Qiu Y, Zhang Y. Screening, management and surveillance for the sessile serrated adenomas/polyps. Int J Clin Exp Pathol. 2014;7:1275-85.

4. Rutter MD, Chattree A, Barbour JA, Thomas-Gibson S, Bhandari P, Saunders BP, Veitch AM, Anderson J, Rembacken BJ, Loughrey MB, et al. British Society of Gastroenterology/Association of Coloproctologists of Great Britain and Ireland guidelines for the management of large non-pedunculated colorectal polyps. Gut. 2015;64:1847-73.

5. Nagy A, Kovacs T, Berki C, Jano Z. Surgical management of villous and tubulovillous adenomas of the rectum. Orv Hetil. 1999;140:2215-9.

6. Chun EM, Kim SW, Lim SY. Prevalence of colorectal adenomatous polyps in patients with chronic obstructive pulmonary disease. Int J Chron Obstruct Pulmon Dis. 2015;10:955-60.

7. Dulskas A, Samalavicius NE, Gupta RK, Zabulis V. Laparoscopic colorectal surgery for colorectal polyps: single institution experience. Wideochir Inne Tech Maloinwazyjne. 2015;10:73-8.

8. Pimentel-Nunes P, Dinis-Ribeiro M, Ponchon T, Repici A, Vieth M, De Ceglie A, Amato A, Berr F, Bhandari P, Bialek A, et al. Endoscopic submucosal dissection: European Society of Gastrointestinal Endoscopy (ESGE) guideline. Endoscopy. 2015:47:829-54

9. Groeben H. Epidural anesthesia and pulmonary function. J Anesth 2006;20:290-9.

10. Hausman Jr MS, Jewell ES, Engoren M. Regional versus general anesthesia in surgical patients with chronic obstructive pulmonary disease: does avoiding general anesthesia reduce the risk of postoperative complications? Anesth Analg. 2015;120:1405-12

11. Licker M, Schweizer A, Ellenberger C, Tschopp JM, Diaper J, Clergue F. Perioperative medical management of patients with COPD. Int J Chron Obstruct Pulmon Dis. 2007:2:493-515.

12. Calin MD, Balalau C, Popa F, Voiculescu S, Scaunasu RV. Colic anastomotic leakage risk factors. J Med Life. 2013;6:420-3.

13. Itoh M, Tsuji T, Nemoto K, Nakamura H, Aoshiba K. Undernutrition in patients with COPD and its treatment. Nutrients. 2013:5:1316-35.

14. Gea J, Martinez-Llorens J, Barreiro E. Nutritional abnormalities in chronic obstructive pulmonary disease. Med Clin (Barc). 2014:143:78-84.

15. Gorek Dilektasli A, Ulubay G, Bayraktar N, Eminsoy I, Oner Eyuboglu F. The effects of cachexia and related components on pulmonary functions in patients with COPD. Tuberk Toraks. 2009;57:298-305.

16. Anker SD, Laviano A, Filippatos G, John M, Paccagnella A, Ponikowski P, Schols AM. ESPEN Guidelines on Parenteral Nutrition: on cardiology and pneumology. Clin Nutr. 2009:28:455-60.

17. Gudmundsson G. Acute exacerbations of chronic obstructive pulmonary disease-review. Laeknabladid. 2015:101:357-62.

18. Kotoc J, Kotocova K, Gatek J, Vrzgula A, Pribula V, Hladik M, Olejnik J. Risk factors for anastomotic leakage following rectal resection-multicenter study. Rozhl Chir. 2014;93:578-82.

19. Raguso CA, Luthy C. Nutritional status in chronic obstructive pulmonary disease: role of hypoxia. Nutrition. 2011;27:138-43.

20. Pitsiou G, Kyriazis G, Hatzizisi O, Argyropoulou P, Mavrofridis E, Patakas D. Tumor necrosis factor-alpha serum levels, weight loss and tissue oxygenation in chronic obstructive pulmonary disease. Respir Med. 2002;96:594-8.

21. Broekhuizen R, Wouters EF, Creutzberg EC, Schols AM. Raised CRP levels mark metabolic and functional impairment in advanced COPD. Thorax. 2006;61:17-22

22. Golub R, Golub RW, Cantu Jr R, Stein HD. A multivariate analysis of factors contributing to leakage of intestinal anastomoses. J Am Coll Surg. 1997; 184:364-72.

23. Iancu C, Mocan LC, Todea-lancu D, Mocan T, Acalovschi I, lonescu D, Zaharie FV, Osian G, Puia Cl, Muntean V. Host-related predictive factors for anastomotic leakage following large bowel resections for colorectal cancer. J Gastrointestin Liver Dis. 2008;17:299-303.
24. Choudhuri AH, Uppal R, Kumar M. Influence of non-surgical risk factors on anastomotic leakage after major gastrointestinal surgery: audit from a tertiary care teaching institute. Int J Crit IIIn Inj Sci. 2013;3:246-9.

25. Kim KH, Kim MC, Jung GJ. Is the rate of postoperative complications following laparoscopy-assisted gastrectomy higher in elderly patients than in younger patients? World J Surg Oncol. 2014;12:97.

26. Khan MR, Bari H, Zafar SN, Raza SA. Impact of age on outcome after colorectal cancer surgery in the elderly - a developing country perspective. BMC Surg. 2011;11:17

27. Rutten HJ, den Dulk M, Lemmens VE, van de Velde CJ, Marijnen CA. Controversies of total mesorectal excision for rectal cancer in elderly patients. Lancet Oncol. 2008;9:494-501.

28. Nasirkhan MU, Abir F, Longo W, Kozol R. Anastomotic disruption after large bowel resection. World J Gastroenterol. 2006;12:2497-504.

29. Siana JE, Rex S, Gottrup F. The effect of cigarette smoking on wound healing. Scand J Plast Reconstr Surg Hand Surg. 1989;23:207-9.

30. Wu K, Wang C, Wang Q, Li H. Regression analysis of controllable factors of surgical incision complications in closed calcaneal fractures. J Res Med Sci. 2014;19:495-501.

31. Parthasarathy $M$, Greensmith $M$, Bowers $D$, Groot-Wassink T. Risk factors for anastomotic leakage after colorectal resection: a retrospective analysis of 17518 patients. Colorectal Dis. 2016.

32. Campo G, Pavasini R, Malagu M, Mascetti S, Biscaglia S, Ceconi C, Papi A, Contoli M. Chronic obstructive pulmonary disease and ischemic heart disease comorbidity: overview of mechanisms and clinical management. Cardiovasc Drugs Ther. 2015:29:147-57.

33. Bozek A, Rogala B, Bednarski P. Asthma, COPD and comorbidities in elderly people. J Asthma. 2016.

34. de Leeuw PW, Dees A. Fluid homeostasis in chronic obstructive lung disease. Eur Respir J Suppl. 2003;46:33s-40.

35. Arques S. Serum albumin and heart failure: recent advances on a new paradigm. Ann Cardiol Angeiol (Paris). 2011;60:272-8.

36. Kumar S, Stevenson WG, John RM. Catheter ablation for premature ventricular contractions and ventricular tachycardia in patients with heart failure Curr Cardiol Rep. 2014;16:522

37. Carlstedt A, Nordgren S, Fasth S, Appelgren L, Hulten L. Epidural anaesthesia and postoperative colorectal motility - a possible hazard to a colorectal anastomosis. Int J Colorectal Dis. 1989;4:144-9.

38. Robertson JP, Puckett J, Vather R, Jaung R, Bissett I. Early closure of temporary loop ileostomies: a systematic review. Ostomy Wound Manage. 2015;61:50-7.

39. Boccola MA, Lin J, Rozen WM, Ho YH. Reducing anastomotic leakage in oncologic colorectal surgery: an evidence-based review. Anticancer Res. 2010;30:601-7.

40. Koskenvuo L, Mustonen $\mathrm{H}$, Renkonen-Sinisalo L, Jarvinen $\mathrm{HJ}$, Lepisto A. Comparison of proctocolectomy and ileal pouch-anal anastomosis to colectomy and ileorectal anastomosis in familial adenomatous polyposis. Fam Cancer. 2015;14:221-7.

41. Mennigen R, Sewald W, Senninger N, Rijcken E. Morbidity of loop ileostomy closure after restorative proctocolectomy for ulcerative colitis and familial adenomatous polyposis: a systematic review. J Gastrointest Surg. 2014;18:2192-200.

\section{Submit your next manuscript to BioMed Central and we will help you at every step:}

- We accept pre-submission inquiries

- Our selector tool helps you to find the most relevant journal

- We provide round the clock customer support

- Convenient online submission

- Thorough peer review

- Inclusion in PubMed and all major indexing services

- Maximum visibility for your research

Submit your manuscript at www.biomedcentral.com/submit 